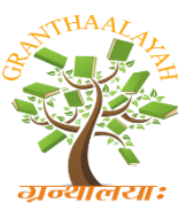
INTERNATIONAL JOURNAL OF RESEARCH - GRANTHAALAYAH A knowledge Repository

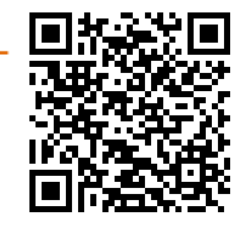

Social

\title{
CONTENT ANALYSIS OF DIAGRAMMATIC REPRESENTATIONS IN UPPER PRIMARY SCIENCE TEXTBOOKS
}

\author{
Dr. Syed Hasan Qasim ${ }^{* 1}$, Sudhansu Shekhar Pandey ${ }^{2}$ \\ ${ }^{* 1}$ Assistant Professor, Department of Teacher Education, SHUATS, Allahabad, India \\ ${ }^{2}$ Department of Teacher Education, SHUATS, Allahabad, India
}

\begin{abstract}
The present study is an attempt to investigate content analysis of diagrammatic representations in upper primary science textbooks based on diagrammatic typology. The study analyzed the distribution of diagrams in different upper primary science book categories. The sample selected consists of a total number of nine 7th grade physics, chemistry and biology textbooks adopted in three Indian Certificate of Secondary Education (I.C.S.E) schools in the Allahabad, India. Content analysis in this research entails a systematic coding and categorizing of the diagrams, drawings, photos, charts and graphs appeared in upper primary school science textbooks. A great amount of diagrams have been used in the upper primary level of science teaching. On average, there are about 1.20 diagrams in physics, 0.80 diagrams in chemistry \& 1.06 diagrams in biology textbooks used per page for the purposes of explaining, presenting or evaluating the scientific domain. The results confirmed that upper primary level of science education demands large quantity of diagrams to facilitate students learning. So content analysis of diagrammatic representations of science textbooks is recommended and teachers should adopt such diagrammatic strategies which increase the level of knowledge of learners. Teachers should teach students through different diagrammatic representations skills and to enhance their academic performance.
\end{abstract}

Keywords: Content Analysis; Iconic; Schematic.

Cite This Article: Dr. Syed Hasan Qasim, and Sudhansu Shekhar Pandey. (2017). "CONTENT ANALYSIS OF DIAGRAMMATIC REPRESENTATIONS IN UPPER PRIMARY SCIENCE TEXTBOOKS." International Journal of Research - Granthaalayah, 5(7), 474-479. https://doi.org/10.29121/granthaalayah.v5.i7.2017.2155.

\section{Introduction}

Textbook is a printed and bound artefact for each year or course of study (Encyclopedia of Education, 2008b). They contain facts and ideas around a certain subject. Today, textbooks are assembled more than they are written. They are not usually written by a single author, nor are they a creative and imaginative endeavour. They are, in fact, usually specially made by a corporation to follow a set standard curriculum for a school system or larger organization, such 
as a province (Encyclopedia of Education, 2008b). Because of the essential role of the text book content in encouraging, providing learner educational needs and making the students learning process easy, the science books content in upper primary school have been assessed and analyzed with respect to diagrammatic representations. Textbooks play a vital role in science teaching and learning. Visual representations are powerful tools for providing learners with explanations of scientific phenomena. Visualizing and understanding a wide range of scientific phenomena are therefore central to facilitating the learner's biological conceptual learning. Among visual representations, diagrams were found critically essential in conveying both abstract and concrete information. Many science teachers report that they frequently use diagrams in their instruction because diagrams can helpful to student understanding in different ways. Well illustrated diagrams can help upper primary students visualize complex scientific and biological phenomena.

Khine M.S. \& Liu Y (2016) summarized the characteristics of diagrammatic usage in the Bahrain primary science books. The textbook analysis method used in the research also provided some insights for researchers interested in analysing the usage of diagrams and other illustrations in science learning contexts. La Due (2015) studied the similarities and differences of visuals used to assess student's knowledge and found that the frequency and type of visuals vary greatly between disciplines. Liu, Y. and Won, M. (2014) and Catley et al (2008) studied the use of different types of diagrams for different purposes in biology textbook provided a view on understanding how different types of diagrams were used in secondary school biology teaching. The study of different types of diagrams provides useful information for science teacher's use of diagrams in their planning and execution of secondary science lessons (Liu, Yung \& David F. Treagust, 2013). Thus, the present study is an attempt to investigate content analysis of diagrammatic representations in upper primary science textbooks based on diagrammatic typology (Hegarty et.al., 1991; Azuma, 1997),

\section{Research Design}

\section{Population and Sample}

The population of the study was all the upper primary science textbooks adopted by all the schools of Allahabad. The sample selected consists of a total number of nine VII $^{\text {th }}$ grade physics, chemistry and biology textbooks adopted in three Indian Certificate of Secondary Education (I.C.S.E) schools in the Allahabad, India.

\section{Coding Scheme}

The diagram coding scheme was created according to the typology proposed by Hegarty, Carpenter, and Just (1991) that classified diagrams used in science teaching context into three types, that are iconic, schematic and charts and graphs. Content analysis in this research entails a systematic coding and categorizing of the diagrams, drawings, photos, charts and graphs appeared in upper primary school science textbooks.

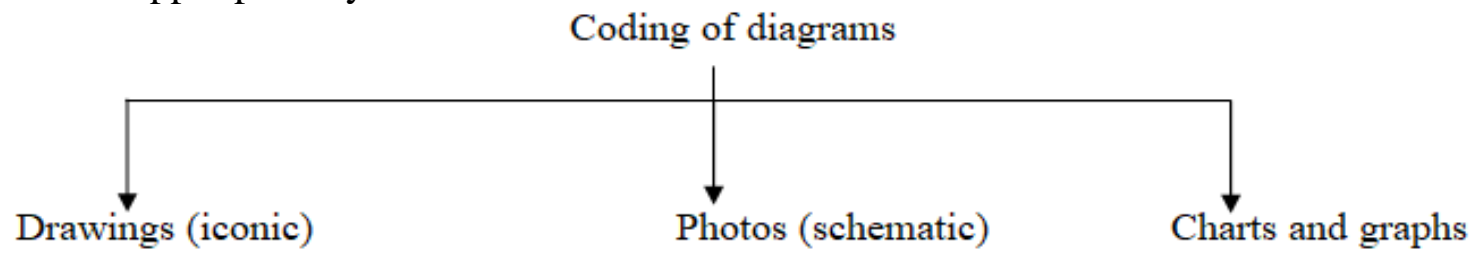


- Iconic diagram - These diagrams are effective in helping students recognize the physical appearance that are available to visual inspection.

- Schematic diagrams - These are highly abstracted from the real world entities but only preserve the physical relationships of the target information.

- Charts and graphs - A chart, also called a graph, is a graphical representation of data.

\section{Objectives}

The aim of this study is to investigate all types of diagrams included in the upper primary science textbooks and to find out the total number of diagrams in each book, the quantity and proportion of each diagram type used in the science textbook. Keeping in view of these objectives the following research question was developed.

1) What is the distribution of visual illustration in upper primary science textbooks?

2) What is the trend of these different diagrammatic representations in upper primary science textbooks?

\section{Methodology}

For this research data collected from upper primary physics, chemistry and biology science textbooks of VII $^{\text {th }}$ class standard of I.C.S.E. board. The data collection begins with predetermined codes and categories. Accordingly, diagrams contained in these textbooks were counted and coded into three types: iconic, schematic, charts and graphs. The research procedure is listed as follow: firstly, all the diagrams in the nine science textbooks were coded. The criterion for coding followed the taxonomy proposed by Hegarty et.al (1991). Secondly, the means of diagrams for each page of textbooks were calculated. The above information is helpful to understand the various diagrams in each book. Thirdly, a percentage test was conducted to examine any differences between the percentage diagrammatic usages in the three school book categories.

\section{Results and Discussions}

In the present study data have been collected by counting the different diagrams of nine upper primary science text books. The obtained data have been analysed by using mean, percentage. Analysis and interpretation of data is presented as follows:-

Table 1: Mean of diagrams usage in the upper primary science textbooks

\begin{tabular}{|l|l|l|l|l|l|}
\hline \multirow{2}{*}{ Book type } & \multirow{2}{*}{ No. Of books } & Iconic & Schematic & Charts and graphs & \multirow{2}{*}{ Total } \\
\cline { 3 - 6 } & & Mean & Mean & Mean & \\
\hline Physics & 3 & 63 & 72 & 19 & 154 \\
\hline Chemistry & 3 & 24.5 & 39.5 & 30.5 & 94.5 \\
\hline Biology & 3 & 46 & 77 & 13.5 & 136.5 \\
\hline
\end{tabular}

The means of diagram inclusion in the three book categories are shown in figure 1. 


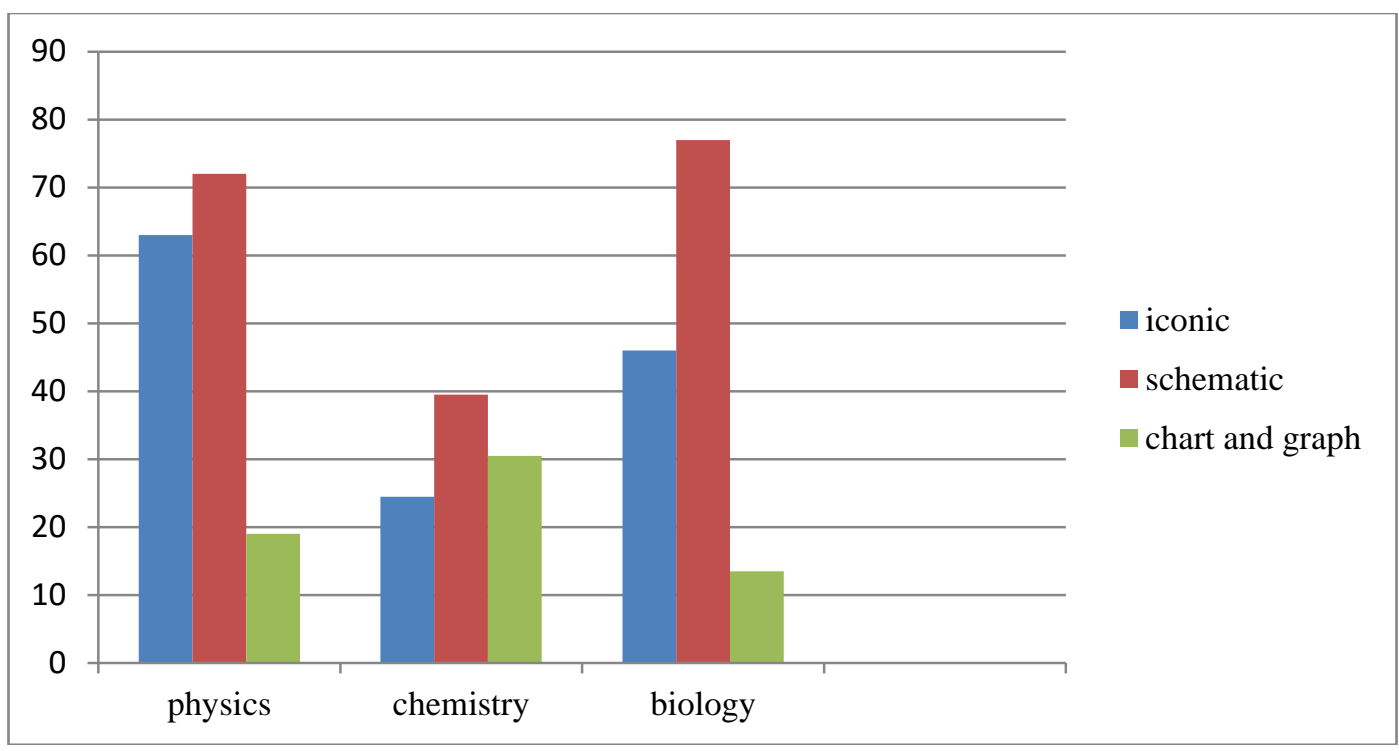

Figure 1: Means of diagram inclusions in the science textbook categories

The three types of diagrams might have played different roles in upper primary science teaching and learning. Results indicate that the usages of three types of diagrams were not found differentiate greatly as they were used in physics, chemistry and biology textbooks. Iconic diagrams (physics $=63$, chemistry $=24.5$, biology=46), schematic diagrams ( physics $=72$, chemistry $=39.5$, biology $=46$ ), charts and graphs (physics $=19$, chemistry $=30.5$, biology $=13.5$ ). In other words, diagrams in upper primary science textbooks might have been use in a consistent method to facilitate the visual illustration of the scientific concepts embedded. Similar study has been found by Liu, Yung \& David F. Treagust, 2013

Table 2: Total number of diagrams and pages in upper primary science textbooks.

\begin{tabular}{|l|l|l|l|}
\hline Types of books & Total number of diagrams & Total number of pages & Diagrams per page \\
\hline Physics & 461 & 384 & 1.20 \\
\hline Chemistry & 281 & 351 & 0.80 \\
\hline Biology & 410 & 387 & 1.06 \\
\hline
\end{tabular}

Upper primary physics science books contain a great amount of diagrammatic illustrations. For the three physics textbooks, there are on average 1.20 diagrams per page used for explaining the scientific concepts. For the three chemistry textbooks, there are on average 0.80 diagrams per page used and for the three biology textbooks, there are on average 1.06 diagrams per page used. So, there are three different types of visual illustrations such as iconic, schematic, charts and graphs were found in different amount in upper primary science textbooks.

Table 3: Percentage of iconic, schematic, charts and graphs used in physics, chemistry and biology textbooks

\begin{tabular}{|l|l|l|l|l|}
\hline Name of diagrams & Physics & Chemistry & Biology & Total Percentage \\
\hline Iconic & $40.90 \%$ & $25.92 \%$ & $33.69 \%$ & $34.67 \%$ \\
\hline Schematic & $46.75 \%$ & $41.79 \%$ & $56.41 \%$ & $48.96 \%$ \\
\hline Charts and graphs & $12.33 \%$ & $32.27 \%$ & $9.89 \%$ & $16.36 \%$ \\
\hline
\end{tabular}




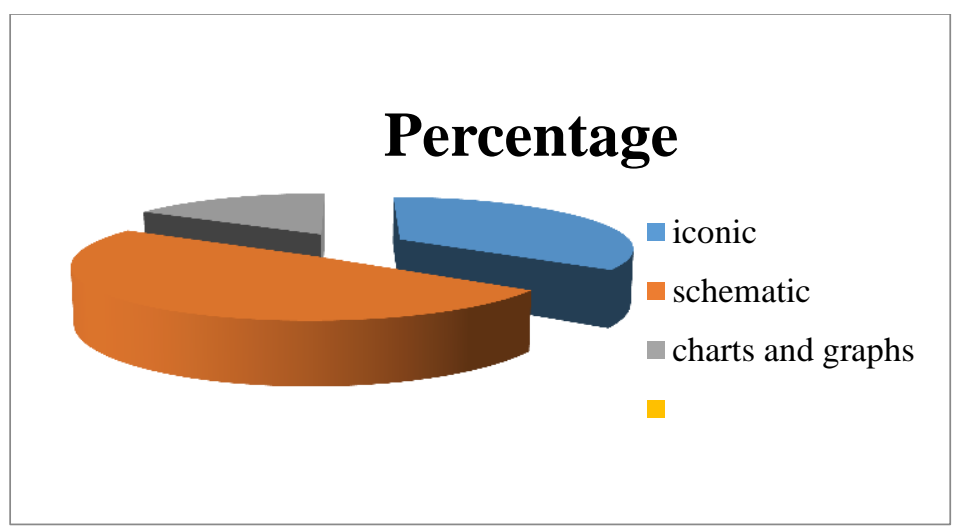

Figure 2: Total percentage of iconic, schematic, charts and graphs used in all science textbooks.

Figure 2, shows total percentage of iconic, schematic, charts and graphs in all upper primary science textbooks. As the results shown in the figure 2, iconic diagrams constitute $34.67 \%$, schematic $48.96 \%$, charts and graphs $16.36 \%$ of the diagram usage in all upper primary science textbooks respectively. In upper primary science textbooks there are very less numbers of charts and graphs $16.36 \%$ are present due to reason that in all upper primary science textbooks schematics diagrams are more inclined to be used for expressing the concept for upper primary students. In physics textbooks usually, many charts and graphs are found but in these selected books, there are less numerical used so charts and graphs are very less i.e., 12.33\%. Similar study has been found by Hegarty et.al, (1991). In chemistry textbooks there are a less number of iconic diagrams $(25.92 \%)$. Due to reason that in upper primary chemistry textbooks schematics diagrams are more inclined to be used for expressing the concept for upper primary students. In biology textbooks there are very less numbers of charts and graphs (9.89\%) are present due to reason that in upper primary biology textbooks schematic diagrams are more inclined to be used for expressing the concepts for upper primary students. Similar studies have been found by Khine, M.S. \& Liu, Y. (2016).

\section{Conclusion}

The study analyzed the distribution of diagrams in different upper primary science book categories. As one of important findings of this upper primary science textbooks analysis research is the diagrams distributional pattern including the frequencies, trends and methods of having scientific content knowledge to be visualized by upper primary learners.

Iconic diagrams keep rich details of the information been contained, learner's therefore have less difficulty in understanding the scientific knowledge and phenomena been demonstrated. This could be one of the reasons that more photos and drawings are used in the upper primary science teaching. It is then reasonable to assume that increasing conceptual understanding and reading skills are necessary for interpreting abstract concepts. In upper primary science textbooks, schematic diagrams are more inclined to be used for explaining the concepts for upper primary students at later levels of schooling. Compared with the iconic and schematic types of diagrams, charts and graphs could be the most intellectually demanding type because knowledge of conventions is essential but not sufficient for comprehending graphs (Hegarty et.al, 1991). Upper primary school students may have two equip themselves with domain knowledge and graphic composition for the complete learning of charts and graphs. 
The results of the study suggest that the three diagram types were found in each upper primary science book, and a distributional pattern could also be summarised to demonstrate the diagrammatic usage among different years of schooling. Though this study didn't aim to discuss the correlation between scientific topic areas and diagrams or the connections between diagrams and other graphic representations, the findings contributes to the literature in several aspects first, it updated Hegurty diagrammatic typology by including iconic, schematic and charts and graphs in examining recent upper primary class VII ${ }^{\text {th }}$ standard science textbooks. Second, it provided empirical findings focusing on the diagrammatic usage at the upper primary level of science education of textbooks. Third, it contributed another approach for textbook research. So content analysis of diagrammatic representations of science textbooks is recommended and teachers should adopt such diagrammatic strategies which increase the level of knowledge of learners. Teachers should teach students through different diagrammatic representations skills and to enhance their academic performance.

\section{References}

[1] Ahtineva, A.(2005). Text book analysis in the service of Chemistry Teaching Universitase Scientiarum, 10, 25-33.

[2] Aldossari A.T., Khaldi J.K., M.H. Altarawneh (2016). CONTENT ANALYSIS OF SCIENCE BOOKS FOR UPPER PRIMARY STAGE. Journal of Education and Practice www.iiste.orgm ISSN 2222-1735 (Paper) ISSN 2222-288X, Vol.7, No.30.

[3] Azuma, R. T. (1997). A SURVEY OF AUGMENTED REALITY. Presence, 6(4), 355-385.

[4] Bale Colin, Neil Taylor and Barend Vlaardingerbroek (2015). "REPRESENTING THE CELL IN DIAGRAMMATIC FORM A STUDY OF STUDENT PREFERENCES.” Volume $61 \backslash$ Number I | March.

[5] Gilbert, J.K. (2007). VISUALIZATION: A META COGNITIVE SKILL IN SCIENCE AND SCIENCE EDUCATION. In J. K. Gilbert (Ed), (pp. 9-28). Dordrecht, the Netherlands: Springer.

[6] Khine M.S. \& Liu Y (2016). "CONTENT ANALYSIS OF THE DIAGRAMMATIC REPRESENTATIONS “ Eurasia Journal of Mathematics, Science \& Technology Education, 2016, 12(8), 1937-1951 doi: 10.12973/eurasia.2016.1288a

[7] Liu, Y., Won M., Treagust (2014). SECONDARY BIOLOGY TEACHERS' USE OF DIFFERENT TYPES OF DIAGRAMS FOR DIFFERENT PURPOSES. Book of Science Teachers use of visual representations; page 103-121, Publisher-Springer International Publishing.

[8] LaDue et.al (2015). VISUAL REPRESENTATIONS ON HIGH SCHOOL BIOLOGY, CHEMISTRY, EARTH SCIENCE AND PHYSICS ASSESSMENTS. Journal of Science Education and Technology, volume 24, Issue 6, pp818-834.

[9] Miller B.S. et.al (2016). IMPROVING DIAGRAMMATIC REASONING IN MIDDLE SCHOOL SCIENCE USING CONVENTIONS OF DIAGRAMS INSTRUCTIONS. Journal of Computer Assisted Learning Aug2016, Vol. 32 Issue 4, p374-390, 17p, 1 Diagram, 8 Charts, 1 Graph.

[10] Singh A.K (2012). Tests, measurements and research methods in behavioural sciences. Bharati Bhawan publishers and distributors.

[11] Vygotsky, L.S. (1978). Mind in society: The development of higher psychological processes. Cambridge, MA: Harvard University Press.

*Corresponding author.

E-mail address: syed.qasim@ shiats.edu.in 